referral is responsible for the patient. However, it was notable that the Scottish CLO suggested that if a request for assessment was made (even if this is before the

original papers

patient had recovered from his/her intoxicated state), the psychiatrist would then have to give an apposite reason for not making the assessment. Clarification is needed on what degree of intoxication means an assessment cannot be undertaken and whether the decision not to assess can be made without contact face to face. The information from the MDU was particularly useful. It suggested that to justify any clinical decision he/she made, a psychiatrist would have to demonstrate it was the accepted practice among a body of psychiatrists. The difficulty is that there did not appear to be a consensus among the psychiatrists surveyed as to the best way to manage such patients. In reality, when and how to assess an individual would partly depend on a balanced consideration of the degree of risk of any suicidal acts as compared with the degree of difficulty in undertaking a reliable assessment because of the level of intoxication. Given that this is known, it seems important that this is clearly recorded in a widely available document. Otherwise a psychiatrist may find his/her clinical judgement called into question because of an apparent lack of a consensus in clinical opinion.

In conclusion, there is no relevant College policy and no previous cases in law on the management of the acutely intoxicated suicidal patient. The medico-legal advice is useful, but the results of the questionnaire survey demonstrate different bodies of opinion within psychiatry. Clearly it is difficult for doctors, who are often junior, to balance the aforementioned issues when managing such patients in emergency settings. We hope that this survey will highlight this problem and encourage sharing of good practice guidelines. It is certainly a topic worthy of inclusion in all induction days for junior psychiatrists.

\section{Declaration of interest}

None.

\section{References}

LAW SOCIETY (2000) Law Society Directory of Solicitors and Barristers. London: The Law Society.

LAW SOCIETY OF SCOTLAND (2000) Scots LawTimes. See http://www. wgreen.co.uk/slt/

MEDICAL DEFENCE UNION (2000) Advice Regarding Psychiatric Risk Assessment London: MDU.

MURPHY, G. \& WETZEL, R. (1990) The lifetime risk of suicide in alcoholism. Archives of General Psychiatry, $\mathbf{4 7}$ 383-392.

PATEL, A., ROY, M. \& WILSON, G. (1972) Self-poisoning and alcohol. Lancet, 2 1099-1103.

SCOTTISH CENTRAL LEGAL OFFICE (2000) Advice on the Management of Clinical Risk. Edinburgh: Scottish Central Legal Office.

SUCKAS, J. \& LONNQVIST, J. (1995) Suicide attempts in which alcohol is involved: a special group in general hospital emergency rooms. Acta Psychiatrica Scandinavica, 91, $36-40$.

Rosemary McCaffery Specialist Registrar, Alyson Lee Specialist Registrar, Pramod Jauhar Consultant Psychiatrist in Substance Misuse, Department of Psychological Medicine, Gartnavel Royal Hospital, Glasgow, *Jan Scott Professor of Psychological Treatments Research, Division of Psychological Medicine, PO Box 96, Institute of Psychiatry,

De Crespigny Park, London SE5 8AF

\title{
Intensive day programme treatment for severe anorexia nervosa - the Leicester experience
}

\section{AIMS AND METHOD}

To look at whether the opening of a day programme for the intensive care of people with severe anorexia nervosa in Leicester had the expected impact on admission rates, length of stay, cost of treatment and also simple measures of whether patients got better. Is this day programme an effective resource?
RESULTS

Since the opening of the day programme, in-patient bed days and overall costs of treatment for local patients have been reduced, and the early results in terms of weight gain and readmission rates are promising.

\section{CLINICAL IMPLICATIONS}

With many areas planning to set up eating disorder services for local patients, it is important to consider which are the best resources to invest in. The experience of a wellestablished specialist service in Leicester has shown that a day programme can be an enriching and cost-effective way to treat patients with anorexia nervosa, but that it does not replace the need for the availability of in-patient beds.
In 1997 the Leicestershire Eating Disorder Service opened a day programme for the treatment of patients with severe low-weight anorexia nervosa. This paper evaluates whether this has improved the service we offer to this group of patients and whether the venture has been cost-effective.

Piran et al (1989) report their outcome from the establishment of intensive out-patient programmes instituted in order to reduce the length of in-patient stay, and suggest that a day hospital programme can provide equally effective treatment of eating disorders when compared with in-patient treatment. Gerlinghoff et al (1998) report the results of a day hospital treatment for patients who would otherwise require in-patient admission. There was significant improvement in eating disorder symptomatology in patients with anorexia, comparable with that reported after in-patient treatment. 


\section{The service}

The Leicestershire Eating Disorder Service currently receives around 300 referrals per year. We serve a population of approximately one million, and in addition receive a growing number of out-of-area referrals. We have six beds on an acute psychiatric ward, an extensive outpatient service offering a variety of treatments and a day programme for the treatment of anorexia nervosa.

Nearly all patients with bulimia nervosa, and the like, are seen totally in out-patient therapy. Any admissions that do occur are brief and usually for psychiatric comorbidity. Even with patients with anorexia nervosa, around two-thirds never receive in-patient treatment and are managed in individual therapy.

There remains a core of patients with low-weight anorexia nervosa who require more intensive treatment. The most usual reasons for this are the inability to shift from in-patient to out-patient status, having a crumbling physical condition or perhaps needing to leave a home environment that is not conducive to change.

Before the day programme was opened, the treatment of anorexia nervosa was dichotomous. In-patient treatment is intensive, lengthy and costly, but provides round-the-clock care. On the other hand, out-patient treatment offers much less intervention and support, at most 1-2 hours weekly. In Leicester there was little or no provision falling between the two treatment modes. With the opening of the Leicester Day Programme, it was envisaged that the following patients would be targeted:

(a) out-patients with low-weight anorexia who are failing to gain or are losing weight (i.e. 'stuck' in therapy)

(b) people with low-weight anorexia who have undergone the in-patient regime and are continuing the task of weight restoration, weight maintenance and therapy.

Therefore, some patients would attend as 'pure' day patients, whereas others would be admitted to the ward and begin attending the day programme from the ward after an initial ward-based period, graduating to day patient care when appropriate. Patients keep the same individual therapist before, during and after any admission to the ward and day programme.

\section{The day programme}

The day programme opened its doors in February 1997. It is open from 10.00 a.m. until 5.15 p.m. 5 days a week and has a maximum capacity of 10 places. Some patients are working towards their prescribed 'plateau weight', and the groups and individual support are very much tailored to support this. When at plateau weight, there is more emphasis on life at home, being back at work, studying, socialising, etc., and the groups and activities are adjusted accordingly. A hot midday meal and a sandwich tea are provided. Keyworkers help with meal planning for breakfasts and weekends. An extensive programme of groups runs throughout the week.

Patients are discussed formally on a weekly basis on the wardround and undergo a review process, usually every 10 weeks, that involves key players, including the patient, to discuss progress in addition to looking at the way forward. The ethos is to provide whatever help patients need to struggle towards weight restoration and recovery, and transitions between out-patient, day patient and in-patient treatment are designed to be as seamless as possible. The day programme is not a facility for patients 'stuck' with anorexia - patients are expected to make steady progress in terms of their weight and are invited to reconsider the options if this is not the case. Patients who progress well in the day programme gradually reduce the number of days they attend, and are discharged to continue with their out-patient therapy.

\section{Data collection}

Data were gathered to look at the number of bed days on the anorexia nervosa regime consumed by local patients in the 3 years prior to the opening of the day programme, and this was compared with the 3 years following (Table 1). Body mass index at admission to and on discharge from the day programme was recorded, as well as at 6 months post-discharge and most recent weight where possible (Table 2). Costs were calculated for in-patient bed days and day programme days, so that an estimate could be made as to whether the day programme had had any impact on bed usage and cost of 'intensive care'. Out of area patients will not be considered in this paper because they were not, in general, able to attend as pure day patients and so it would not be expected that the addition of this facility would change their length of in-patient stay.

\section{Results}

There were 12 local patients admitted for intensive care between February 1994 and January 1997. Fifteen local patients started their admissions to the day programme between February 1997 and January 2000, including 10 patients who had ward admissions and 5 pure day patients. The 5 pure day patients most probably would have been admitted to the ward if the day programme had not been available.

Of note is the observation that admission body mass index values for the later cohort are higher - this is skewed by a couple of patients who were complicated in other ways.

Readmission rates were looked at. The 1994-1997 cohort was followed up for an average of 4.2 years postdischarge and $33 \%$ of them were readmitted. All readmissions were within 21 months of discharge. The 1997-2000 cohort was followed up for a mean of 1.45 years post-discharge and the readmission rate was $20 \%$.

\section{Discussion}

This article has looked at the success, in crude terms, of a specially developed day programme treatment for patients with severe low-weight anorexia. This is an important issue because many areas of the UK are 
Table 1. Average bed days and cost per patient in the 3 years before and after opening of the day programme

original papers
February 94-January 97

2601 days (average 217 bed

Day programme days used as in-patient

(enhancement) at $\mathrm{f} 111.07$ per day

Day programme days used as out-patient

at $£ 111.07$ per day

Average total cost per patient
(3 years pre-day programme)

12 in-patients

days per patient, $\mathrm{f} 47030$ )

February 97-January 00

(3 years post-day programme)

10 -inpatients, 5 'pure' day patients

1348 days (average 90 bed days per patient, f19 506)

755 (average 50 per patient, f5590) 1

1542 (average 103 per patient, f11417)

£47030 (s.d. £21000) $£ 36514(78 \% \text { of } £ 47030)^{1}$ (s.d. £25 000)

1. A total of 755 day programme days were used by in-patients as an enhancement to their in-patient stay. Within $2-3$ weeks of admission to the ward, in-patients begin attending the day programme, and continue with this on discharge from the ward. If these figures are included, the average price per patient increases, as shown. However, out-of-area patients are not charged extra for this enhancement to in-patient stay.

\begin{tabular}{lllll}
\hline Table 2. Mean body mass index (BMI) values and ranges & \\
& $\begin{array}{l}\text { BMl on admission } \\
\text { to 'intensive care' }\end{array}$ & $\begin{array}{l}\text { BMl on discharge } \\
\text { from 'intensive care' }\end{array}$ & $\begin{array}{l}\text { BMl } 6 \text { months after } \\
\text { discharge from } \\
\text { 'intensive care' }\end{array}$ & Most recent BMI \\
\hline $\begin{array}{l}\text { Feb. 1994-Jan. 1997 } \\
\text { Feb. 1997-Jan. } 2000\end{array}$ & $\begin{array}{l}13.5(10.3-18.7) \\
15.0(10.8-18.4)\end{array}$ & $\begin{array}{l}17.6(13.5-21.2) \\
18.7(13.0-21.9)\end{array}$ & $\begin{array}{l}17.2(12.1-23.4) \\
18.0(15.2-21.9)\end{array}$ & $18.7(11.5-23.4)$ \\
$18.8(13.8-22.6)$
\end{tabular}

underresourced in terms of provision for patients with eating disorders and are considering how the needs of such a population may best be met. There is a mushrooming of eating disorder services and plans for day programmes. The experiences of an established service may be of value.

The majority of staff and patients of the Leicester Eating Disorder Service would probably say that the addition of the day programme has greatly enriched the experience of those admitted to hospital for treatment and has provided a useful option for some patients who did not wish to be in-patients. It has also made the transition between in-patient and out-patient care much smoother, and provided patients with more preparation to deal with 'life on the outside'. There would be little doubt that the day programme is a good thing. However, the examination of such opinions was not the purpose of this paper.

There are factors to be considered when looking at the results. First, the day programme has evolved and improved with experience and, as with any project, there were teething problems. There was a need to have a change of culture, in that the staff and patients were used to admissions being long. This led to anxiety and resistance to early discharge to day programme status. Some of the day programme staff had little experience of work with eating disorders initially. Perhaps with a more mature venture the results in terms of reducing admission lengths and so on may improve. Factors that might increase the efficacy of the day programme (and the cost) would be to have extended hours and to be open 7 days a week, so that patients could have three meals a day in a supportive environment.

Despite these factors, since the opening of the day programme the in-patient bed days and overall costs of treatment for local patients have been reduced, and the early results in terms of weight gain and readmission rates are promising.

It may be that because we have the luxury of inpatient, day patient and out-patient care, we use our inpatient beds more freely than if patients had to be sent elsewhere. That is, if we had no beds, would we manage more of our severely ill patients as pure day patients? We suspect so.

\section{Declaration of interest}

None.

\section{References}

GERLINGHOFF, M., BACKMUND, H. \& FRANZEN, U. (1998) Evaluation of a day treatment programme for eating disorders. European Eating Disorders Review, 6, 96-106.

PIRAN, N., LANGDON, C., KAPLAN, A. et al (1989) Evaluation of a day hospital programme for eating disorders. International Journal of Eating Disorders, 8(5), 523-532.

*Helen Birchall Consultant Psychiatrist, Robert L. Palmer Honorary Consultant Psychiatrist, Joanne Waine Research Assistant, Kathy Gadsby Therapist, Nick Gatward Day Programme Manager, Leicester Eating Disorder Service, Brandon Mental Health Unit, Leicester General Hospital, Gwendolen Road, Leicester LE5 4PW 